\title{
Pharmacological Characterization of Calcium Currents and Synaptic Transmission between Thalamic Neurons in vitro
}

\author{
F. W. Pfrieger, N. S. Veselovsky, ${ }^{a}$ K. Gottmann, and H. D. Lux \\ Department of Neurophysiology, Max-Planck-Institute for Psychiatry, D-W-8033 Planegg-Martinsried, Germany
}

\begin{abstract}
We recorded from pairs of cultured, synaptically connected thalamic neurons. Evoked excitatory postsynaptic currents (EPSCs) reversed at $+17 \mathrm{mV}$ and were blocked reversibly by $1 \mathrm{~mm}$ kynurenic acid, a glutamate receptor antagonist. NMDA and non-NMDA receptors mediated excitatory postsynaptic responses, as shown by selective block of EPSC components with $50 \mu \mathrm{M}( \pm)$-2-amino-5-phosphonopentanoic acid and $10 \mu \mathrm{m}$ 6,7-dinitroquinoxaline-2,3-dione, respectively. Inhibitory postsynaptic responses were evoked less frequently and were blocked by the GABA ${ }_{A}$ receptor antagonist $(-)$-bicuculline methochloride. The pharmacological profiles of whole-cell calcium currents and evoked EPSCs were compared. With $50 \mu \mathrm{m}$ cadmium chloride (Cd), whole-cell low voltage-activated (LVA) calcium currents were reduced in amplitude and high voltage-activated (HVA) calcium currents and excitatory synaptic transmission were completely blocked. This suggests that the residual calcium influx through LVA channels into the presynaptic terminal does not suffice to trigger transmitter release. A saturating concentration of $\omega$-conotoxin GVIA $(\omega-\mathrm{CgTx})(2.5 \mu \mathrm{M})$ blocked onethird of whole-cell HVA calcium currents and evoked EPSCs. The dihydropyridine nifedipine $(50 \mu \mathrm{M})$ reversibly reduced whole-cell HVA calcium currents in a voltage-dependent manner but not excitatory synaptic transmission. $C d$ and $\omega$ CgTx did not alter amplitude distributions of miniature EPSCs, demonstrating that the inhibition of synaptic transmission was due to block of presynaptic calcium channels. We conclude that excitatory glutamatergic transmission in thalamic neurons in vitro was mediated mainly by HVA calcium currents, which were insensitive to $\omega$ - $\mathrm{CgTx}$ and nifedipine.
\end{abstract}

Synaptic transmission is triggered by the spike-induced influx of calcium ions through voltage-activated calcium channels into the presynaptic terminal (Katz, 1969). The characterization of presynaptically located calcium channels is thus crucial for the analysis of synaptic transmission. In general, two main classes of calcium channels were distinguished by their voltage dependence of activation, low voltage-activated (LVA or T-type) and high voltage-activated (HVA) calcium channels (Carbone

Received Feb. 24, 1992; revised May 15, 1992; accepted June 8, 1992.

This work was supported by the Deutsche Forschungsgemeinschaft SFB 220 (A1). We thank Mrs. H. Tyrlas for skillful technical assistance and Mr. H. Zucker and Mr. G. Braendle for introduction in AuTEsP programming

Correspondence should be addressed to Frank W. Pfrieger, Max-Planck-Institute for Psychiatry, Department of Neurophysiology, Am Klopferspitz 18A, DW-8033 Planegg-Martinsried, Germany.

aPresent address: A. A. Bogomoletz Institute of Physiology, Bogomoletzstreet 4, Kiev-24, 252601 GSP Ukrainia.

Copyright (C) 1992 Society for Neuroscience $0270-6474 / 92 / 124347-11 \$ 05.00 / 0$ and Lux, 1984; Fedulova et al., 1985). HVA calcium channels have heen further subdivided into L- and N-type due to their biophysical properties and their sensitivity to organic agents (Fox et al., 1987a,b; for reviews of calcium channels, see Miller, 1987; Tsien et al., 1988; Bean, 1989; Carbone and Swandulla, 1989; Wray et al., 1989; Hess, 1990; Swandulla et al., 1991; Tsien et al., 1991). Biophysical criteria for calcium channel classification have been challenged (see reviews in Carbone and Swandulla, 1989; Swandulla et al., 1991) by a number of recent reports showing that $\mathrm{L}$ - and $\mathrm{N}$-type calcium channels cannot be distinguished due to single-channel conductances and inactivation kinetics of whole-cell currents (Swandulla and Armstrong, 1988; Aosaki and Kasai, 1989; Plummer et al., 1989; Schroeder et al., 1990; Plummer and Hess, 1991).

The classification of HVA calcium channels based on pharmacological criteria is widely used. According to this, dihydropyridine (DHP)-sensitive calcium channels are termed L-type (see reviews cited ahove). Non-DHP-sensitive calcium currents, which are blocked by $\omega$-conotoxin GVIA $(\omega$-CgTx), a peptide toxin of marine cone snails (Gray et al., 1988; Sher and Clementi, 1991), have been termed N-type (Plummer et al., 1989; see reviews in Miller, 1987; Bean, 1989; Tsien et al., 1991; Ntype calcium channels are critically discussed in Carbone and Swandulla, 1989; Hess, 1990; Sher and Clementi, 1991). HVA calcium currents, which are not sensitive to either DHPs or $\omega$ $\mathrm{CgTx}$ (further referred to as non-L-/non-N-type), have been described in peripheral and central neurons (Mogul and Fox, 1991; Regan et al., 1991). With a fraction of funnel-web spider toxin, a calcium channel with properties distinct from $\mathrm{T}$-, L-, and $\mathrm{N}$-type channels was isolated from rat cerebellum and squid optic lobe and termed P-type (Llinás et al., 1989; see review in Tsicn ct al., 1991).

Calcium channels in presynaptic terminals, which mediate transmitter release, have been the subject of numerous investigations (see reviews in Augustine et al., 1987; Miller, 1987, 1990; Smith and Augustine, 1988; see also Stanley et al., 1991). Since presynaptic nerve terminals of most neuronal cell types are not accessible to electrophysiological measurements, the biophysical properties of their calcium channels are only known for a few preparations of invertebrates (Edmonds et al., 1990; see review in Augustine et al., 1987) and vertebrates (Lemos and Nowycky, 1989; Yawo, 1990; Stanley and Goping, 1991).

The role of LVA calcium channels in synaptic transmission has been rarely investigated, as highly selective blockers of this calcium channel type are currently not available. The pharmacological profile of presynaptic HVA calcium currents has been investigated intensively (see reviews cited above and also Tsien et al., 1988; Bcan, 1989). $\omega$-CgTx-sensitive but DHPinsensitive calcium channels (often termed $\mathrm{N}$-type) seem to play 
a dominant role in synaptic transmission as indicated by studies on sympathetic neurons (Hirning et al., 1988), hippocampal slices (Kamiya et al., 1988; Dutar et al., 1989; Krishtal et al., 1989; Horne and Kemp, 1991), and brain synaptosomes (Reynolds et al., 1986) of the rat and also on nerve terminals of the Xenopus hypophysis (Obaid et al., 1989) and the chicken ciliary ganglion (Stanley and Atrakchi, 1990). Most investigators agree that L-type calcium channels do not mediate release of classical transmitters. It has been proposed, however, that L-type channels are involved in the release of peptides stored in dense-core vesicles, which is activated by high-frequency stimulation (Hirning et al., 1988; Lemos and Nowycky, 1989; De Camilli and Jahn, 1990). DHPs affect release of substance $P$ in dorsal root ganglion cells (Perney et al., 1986; Holz et al., 1988) after potassium-evoked depolarization.

The majority of investigations on presynaptic calcium channels of central neurons deal with hippocampal preparations; other brain regions, however, are poorly studied. The thalamus (Jones, 1985; Shepherd, 1990) is a key structure for central information processing ("gateway to the neocortex"; Shepherd, 1990). Oscillatory properties of thalamic relay neurons have been intensively investigated (Steriade et al., 1990). Whole-cell HVA calcium currents of thalamic neurons have not been characterized pharmacologically so far, and it is not known which types are involved in synaptic transmission.

We established a long-term culture of embryonic thalamic neurons with excitatory glutamatergic and inhibitory GABAergic synaptic responses. Evoked synaptic transmission was studied with pair recordings. Presynaptic calcium currents mediating excitatory synaptic transmission were investigated with a pharmacological approach, comparing the pharmacological profiles of whole-cell calcium currents and evoked excitatory postsynaptic currents (EPSCs).

\section{Materials and Methods}

Cell culture. Pregnant Wistar rats were anesthetized and decapitated. Whole thalami were dissected out of embryos (embryonic day 17) and triturated with fire-polished Pasteur pipettes without prior enzymatic treatment. Dissociated cells were plated at low density $\left(5 \times 10^{4} / \mathrm{cm}^{2}\right)$ in polyornithine-laminin-coated culture dishes and cultured in Eagle's basal medium with addition of $10 \%$ fetal horse serum, L-glutamine, glucose, insulin, penicillin, and streptomycin. During the first days in culture, intensive neurite outgrowth occurred and non-neuronal cells grew to a confluent monolayer. After $4 \mathrm{~d}$, cytosine- $\beta$-D-arabinofuranoside hydrochloride $(10 \mu \mathrm{M})$ was added to the culture medium, in order to minimize proliferation of glial cells. Two different morphological types of neurons could be distinguished showing either bi- or multipolar neurite arborization.

Electrophysiological recordings, data acquisition, and analysis. Wholecell currents were recorded at room temperature with the patch-clamp technique (Hamill et al., 1981). Patch electrodes (5-7 M $\Omega$ ) were fabricated from borosilicate glass and filled with a solution containing a physiologically low chloride concentration (100 mM K-gluconate, 10 $\mathrm{mM} \mathrm{KCl}, 0.25 \mathrm{~mm} \mathrm{CaCl}_{2}, 10 \mathrm{~mm}$ EGTA, $20 \mathrm{~mm}$ HEPES, $0.1 \mathrm{~mm} \mathrm{Mg-}$ ATP, pH 7.3). The extracellular solution contained $125 \mathrm{mM} \mathrm{NaCl}, 5$ $\mathrm{mm} \mathrm{KCl}, 5 \mathrm{~mm} \mathrm{CaCl}_{2}$, and $20 \mathrm{~mm}$ HEPES, adjusted to $\mathrm{pH}$ 7.3. In order to record nonevoked miniature EPSCs (mEPSCs), spike activity was blocked with $1 \mu \mathrm{M}$ tetrodotoxin (TTX), and inhibitory input was suppressed with $50 \mu \mathrm{M}(-)$-bicuculline methochloride. In order to record calcium currents, extracellular sodium was replaced by choline, and intracellular potassium was substituted for by cesium chloride with tetraethylammonium chloride ( $20 \mathrm{~mm}$ ) added. Discrimination of LVA and HVA calcium currents was based on their voltage dependence of activation (Carbone and Lux, 1984).

For analog-digital conversion, stimulation, and data analysis, pCLAMP software (Axon Instruments Inc.) was used. mEPSCs were analyzed with AutesP software. Critical detection parameters were the time-to-peak and the amplitude. The detection threshold was chosen according to the root-mean-square noise level of the recorded sample. This was estimated by the standard deviation (SD) of 1500 amplitude values measured at defined time intervals. The detection threshold was set at the twofold SD value. Values of peak and noise amplitudes were determined for each mEPSC and binned.

Drug application. In order to characterize calcium currents and postsynaptic responses pharmacologically, a spatially selective superfusion technique (Streit and Lux, 1989; Gottmann et al., 1991) was used (Fig. $1 A$ ). In order to ensure the application of a saturating concentration, in some experiments $\omega$-CgTx (Bachem Biochemica $\mathrm{GmbH}$ ) was applied dropwise into the culture dish (final concentration, 2.5 and $5 \mu \mathrm{M}$, respectively). Nifedipine (Bayer) was dissolved in $0.25 \%$ dimethylsulfoxide, which itself had no effect. Experiments with this drug were carried out in a dimmed room. 6,7-Dinitroquinoxaline-2,3-dione (DNQX), $( \pm$ )2-amino-5-phosphonopentanoic acid (AP-5), kynurenic acid, (-)-bicuculline methochloride were from Sigma Chemie GmbH; ethosuximide was a kind gift of Goedecke $A G$ and Desitin $\mathrm{GmbH}$.

\section{Results}

Postsynaptic currents evoked by stimulation of presynaptic neurons

After $10 \mathrm{~d}$ in vitro, thalamic neurons had formed functional synaptic contacts as spontaneous postsynaptic currents could be recorded from neuronal cells (see below). In order to study evoked synaptic transmission, we recorded from pairs of neurons. Presynaptic cells, held at $-70 \mathrm{mV}$, were stimulated by depolarizing pulses, and evoked postsynaptic whole-cell currents (Fig. 1B) were recorded at different holding potentials. The internal solution contained a low concentration of chloride. This allowed discrimination of EPSCs and inhibitory postsynaptic currents reversing near $15 \mathrm{mV}$ and $-60 \mathrm{mV}$, respectively. Extensive spontaneous synaptic activity distorted evoked responses and therefore was minimized by culturing thalamic neurons at low cell density $\left(5 \times 10^{4} / \mathrm{cm}^{2}\right.$; Fig. $\left.1 A\right)$. This also increased the probability of finding a pair of neuronal cells with synaptic contacts.

Overall, 53 synaptically connected pairs were analyzed. The latency between the peak of the presynaptic action potential and the onset of the postsynaptic response ranged from $1.5 \mathrm{msec}$ to $10 \mathrm{msec}$ with a mean $\perp \mathrm{SD}$ value of $4.4 \pm 2.1 \mathrm{msec}(n=53$; Fig. $1 B$ ). Latencies greater than $10 \mathrm{msec}$, which were presumably due to polysynaptic activation, were rarely observed, and these cell pairs were excluded from the analysis. A similar range of synaptic latencies has been reported previously for hippocampal synaptic transmission in culture (see, e.g., Scholz and Miller, 1991). In in situ recordings, shorter synaptic latencies have been measured (see, e.g., Sayer et al., 1989), presumably due to higher ambient temperature and the relatively intact glial sheath around neurons in slices, which is lost in culture.

In 45 pair recordings, EPSCs were evoked. Seven out of the 12 EPSCs tested reversed at an average potential of $+17 \pm 8$ $\mathrm{mV}$ (Fig. $2 A$ ), indicating that these currents were caused by a nonselective cationic conductance. Five out of the 12 EPSCs tested did not reverse at holding potentials up to $+40 \mathrm{mV}$, presumably due to an electrotonically distant location of synapses, where the membranc potential cannot be effectively controlled. The mean amplitude of evoked EPSCs was $506 \pm 330$ pA. Currents had a mean time-to-peak of $3.5 \pm 1.7 \mathrm{msec}(n=$ 45) and decayed within $20 \mathrm{msec}$.

Evoked postsynaptic currents were characterized pharmacologically with a spatially selective superfusion technique (Fig. 1 $A$; Streit and Lux, 1989; Gottmann et al., 1991). EPSCs were reversibly blocked by the glutamate antagonist kynurenic acid ( $1 \mathrm{~mm} ; n=10$; not shown), indicating that these currents were 

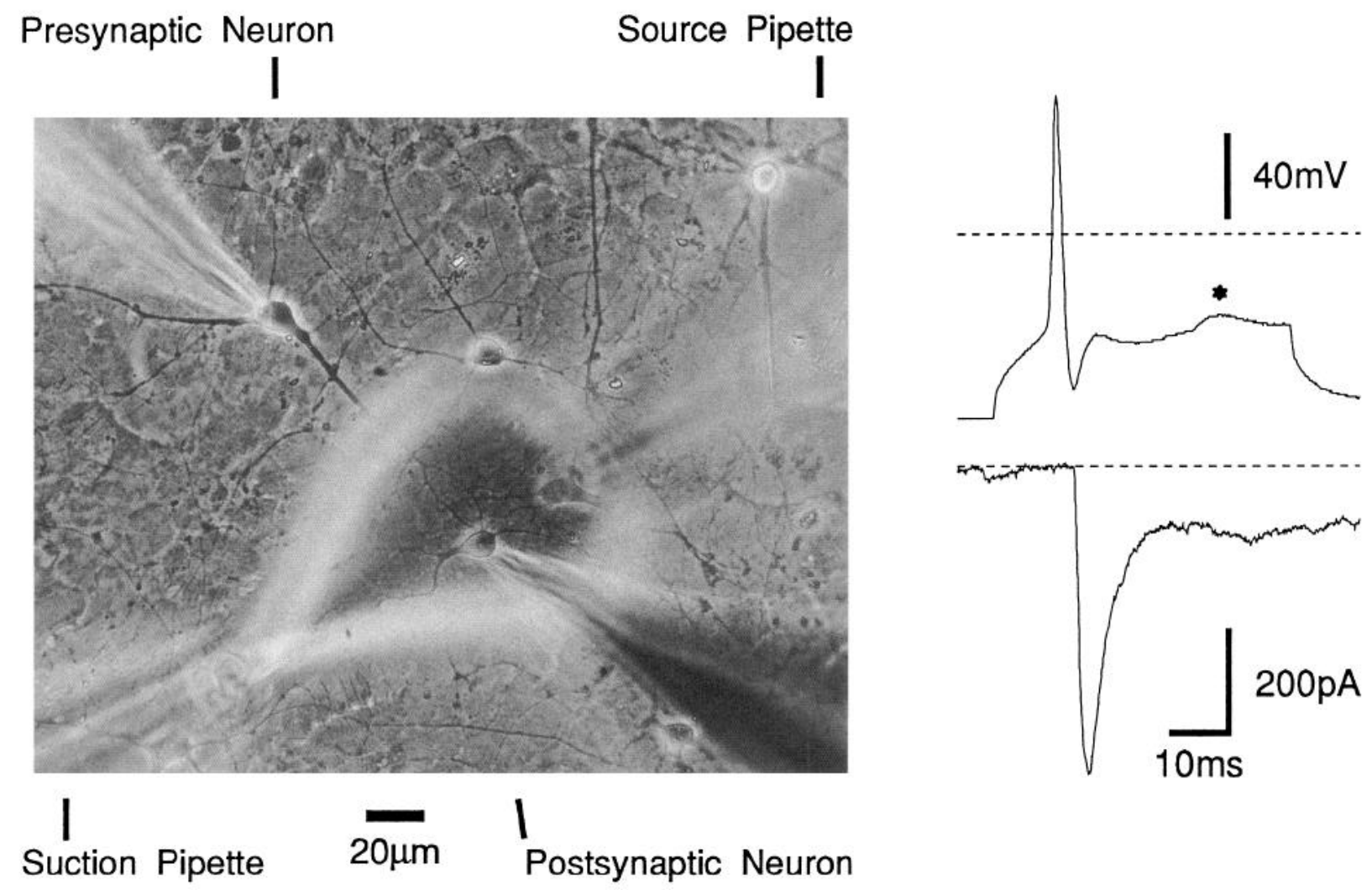

Figure 1. Pair recording of evoked synaptic transmission between cultured thalamic neurons. A, Photomicrograph of thalamic neurons in vitro with micropipettes for recording and selective superfusion. B. Pair recording of evoked excitatory synaptic transmission from two thalamic neurons in vitro. Upper panel, Current-clamp recording of a presynaptic action potential, evoked by current injection into the presynaptic cell. Asterisk, subthreshold depolarization, which did not elicit a second postsynaptic response. Lower panel, Voltage-clamp recording of an EPSC, evoked by the presynaptic spike. The postsynaptic cell was held at $-70 \mathrm{mV}$. The broken lines indicate zero membrane potential and current, respectively.

mediated by glutamate receptors. The contribution of NMDA and non-NMDA receptor subtypes to evoked EPSCs was determined with selective antagonists. DNQX $(10 \mu \mathrm{M})$, a nonNMDA receptor antagonist, blocked $88 \pm 10 \%(n=5$; Fig. $2 B)$ of the peak current amplitude reversibly, leaving a slowly decaying component. AP-5, which selectively blocks the NMDA receptor subtype, completely abolished the slow current component with little effect on the peak amplitude (50 $\mu \mathrm{M} ; n=5$; Fig. $2 C$ ). Thus, non-NMDA and NMDA receptors mediated fast and slow components of excitatory postsynaptic responses. Rundown of evoked EPSCs was observed in 11 out of 13 pairs tested, ranging from $-2 \%$ to $-23 \%$ per min, with an mean of $-7 \pm 6 \%$ per min.

In 8 out of the 53 neuronal cell pairs, investigated, postsynaptic currents reversed at an average potential of $-53 \pm 6 \mathrm{mV}$ $(n=8$; Fig. $3 A$ ), as to be expected for inhibitory responses due to chloride currents. The mean time-to-peak was $5.3 \pm 1.4 \mathrm{msec}$ $(n=8)$. The currents decayed slowly, lasting for more than 20 msec. Since inhibitory synaptic responses were rarely evoked, spontaneous outward postsynaptic currents were characterized pharmacologically in cells held at $-30 \mathrm{mV}$ (Fig. $3 B$ ). These were blocked by (-)-bicuculline methochloride $(50 \mu \mathrm{M})$, a selective $\mathrm{GABA}_{\mathrm{A}}$ antagonist (Fig. 3C). Thus, excitatory, glutamatergic, and, less frequently, inhibitory GABAergic synapses had formed between cultured thalamic neurons. All further investigations were carried out on excitatory, glutamatergic synapses with a nominally magnesium-free extracellular solution to allow activation of postsynaptic NMDA receptors.

\section{mEPSCs due to spontaneous transmitter release}

In order to characterize calcium channels mediating presynaptic calcium influx, drug effects on postsynaptic receptors had to be excluded. Miniature postsynaptic currents, isolated by adding TTX to the extracellular solution, are due to probabilistic release of transmitter quanta and independent of presynaptic calcium influx. Drugs affecting postsynaptic receptors would alter the amplitude distribution of miniature postsynaptic currents. With impulse activity suppressed by TTX $(1 \mu \mathrm{M})$ and inhibitory input blocked by (-)-bicuculline methochloride $(50 \mu \mathrm{M})$, mEPSCs were recorded (Fig. 4A) that could be blocked reversibly by kynurenic acid ( $1 \mathrm{~mm} ; n=3$; not shown). The currents were thus due to quantal release of excitatory amino acids from presynaptic terminals.

mEPSCs, reaching a certain threshold amplitude within a defined time, were detected. The detection threshold was chosen according to the noise level of the entire recorded sample. Amplitudes of mEPSCs ranged from -80 to $-5 \mathrm{pA}$ (Fig. $4 B$ ). mEPSCs occurred with frequencies up to 40 events per second. 

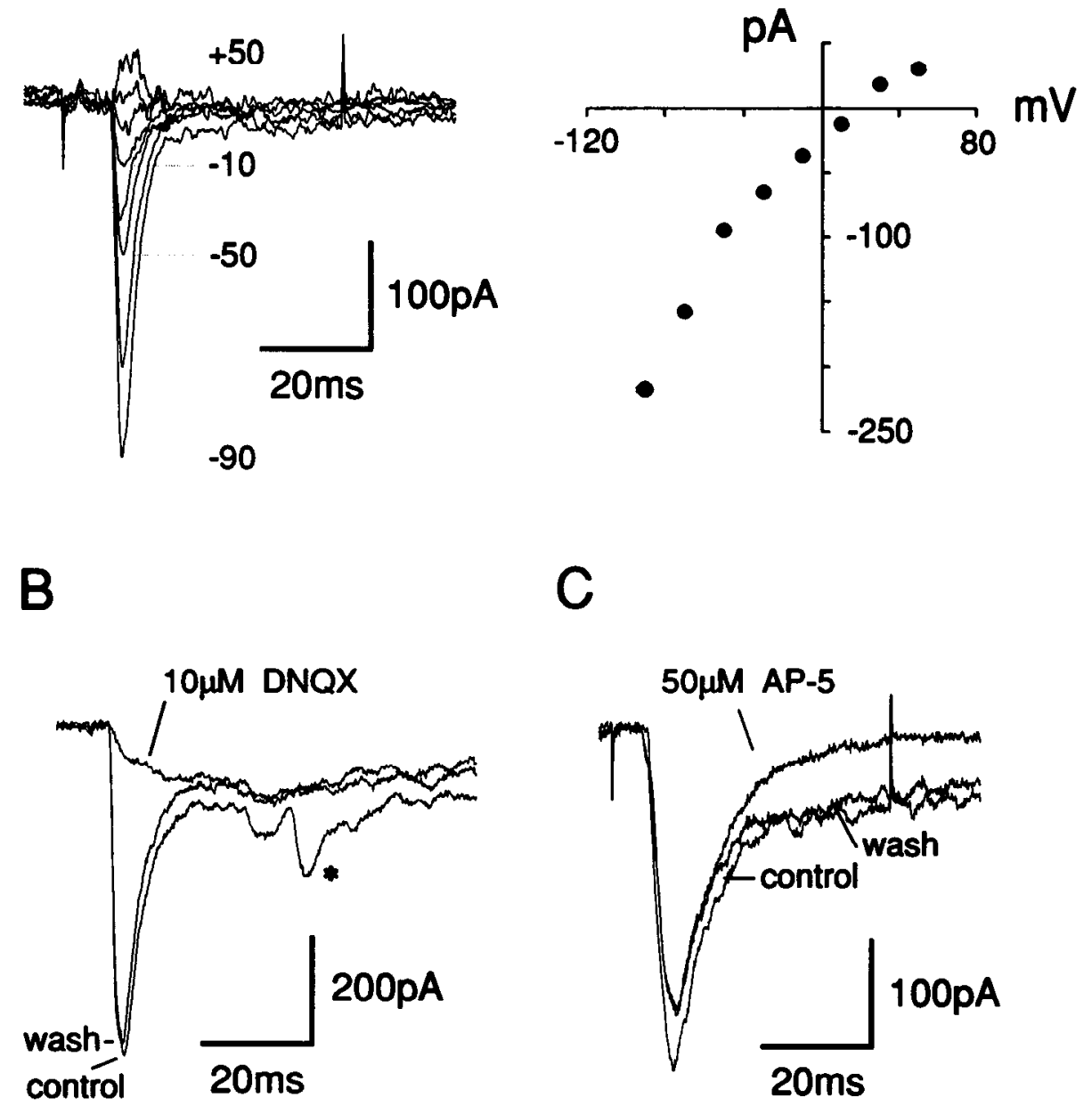

C

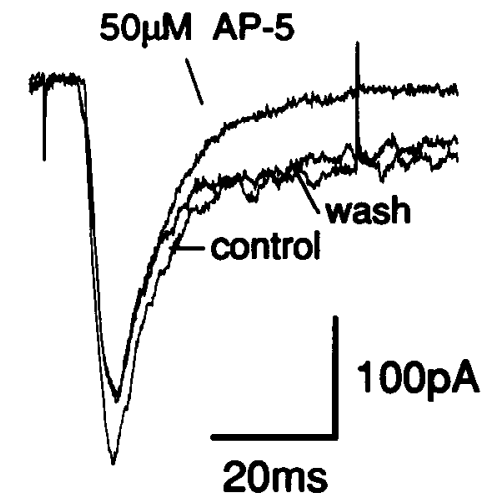

$20 \mathrm{~ms}$

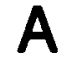 \\ A}

$-90$
Figure 2, Characterization of evoked EPSCs in thalamic neurons in vitro. $A$, Reversal potential. Left panel, The postsynaptic neuron was held at different membrane potentials (indicated in millivolts; $20 \mathrm{mV}$ steps). Right panel, $I-V$ relationship of EPSCs averaged from two consecutive trials (peak amplitude plotted against holding potential). $B$ and $C$, Pharmacological characterization; holding potential, -70 $\mathrm{mV} . B$, Reversible block of the fast current component by $10 \mu \mathrm{M}$ DNQX, a selective blocker of non-NMDA glutamate receptors. Asterisk, spontaneous EPSC. $C$, The slow current component was reversibly blocked by $50 \mu \mathrm{M}$ AP- 5 and thus due to activation of NMDA glutamate receptors.
Amplitude distributions of mEPSCs were asymmetrical (Fig. $4 A$ ), with the smallest ampiitude $(<5 \mathrm{pA})$ buried in the recording noise.

\section{Voltage-dependent calcium currents}

Voltage-activated whole-cell calcium currents of thalamic neurons were recorded in a sodium-free solution and elicited by depolarizing pulses from $-70 \mathrm{mV}$ to different holding potentials. Cells with short neurites were chosen, in order to minimize inadequate voltage control. Both main types of calcium currents were present in thalamic neurons. LVA calcium currents activated at $-50 \mathrm{mV}$ (mean amplitude, $-97 \pm 86 \mathrm{pA} ; n=51$ ). Amplitudes of LVA calcium currents fell in two groups with different ranges. The majority of neurons had LVA currents with amplitudes ranging from -20 to $-165 \mathrm{pA}$ and a mean value of $72 \pm 37 \mathrm{pA}(n=46)$. A minor group of neurons had prominently large LVA current components with amplitudes between -267 to $-437 \mathrm{pA}$ (mean value, $-326 \pm 70 \mathrm{pA} ; n=$ 5). LVA calcium currents inactivated at $-30 \mathrm{mV}$ within 50 msec.

HVA calcium currents were elicited at $-20 \mathrm{mV}$ (mean amplitude, $-470 \pm 380 \mathrm{pA} ; n=52$ ) and showed little inactivation during a depolarizing voltage step to $+10 \mathrm{mV}$ (Fig. $4 B$ ). Rundown of HVA calcium currents was observed in seven out of nine cells tested, ranging from $-1 \%$ to $-7 \%$ per min with a mean of $-5 \pm 3 \%$ per min, which did not differ significantly from rundown of evoked EPSCs. In this study, LVA and HVA calcium currents were activated at $-30 \mathrm{mV}$ and $+10 \mathrm{mV}$, respectively.

Effects of calcium channel blockers on whole-cell calcium currents, evoked synaptic transmission, and $M E P S C S$

We first determined the contribution of LVA and HVA calcium channels to calcium influx into presynaptic terminals and thus evoked transmitter release. Micromolar concentrations of $\mathrm{Cd}$ block HVA calcium channels, while leaving LVA calcium channels relatively unaffected (Fox et al., 1987a; Swandulla and Armstrong, 1989). In thalamic neurons, $50 \mu \mathrm{M} \mathrm{Cd}$ reversibly reduced whole-cell LVA calcium currents by $42 \pm 14 \%(n=7$; Fig. $5 A)$. HVA calcium currents were reversibly and almost completely blocked (93 $\pm 7 \%$ reduction; $n=8$; Fig. $5 A$ ). Glutamatergic EPSCs, evoked by presynaptic stimulation, were completely and reversibly blocked ( $n=7$; Fig. $5 B$ ). Frequency distributions of mEPSC amplitudes were not affected $(n=7$; Fig. $5 C)$, indicating that the inhibition of synaptic transmission was due to block of presynaptic calcium channels. Lower concentrations of Cd (10 $\mu \mathbf{M}$ and $20 \mu \mathbf{M})$ still affected LVA calcium currents $(21 \pm 8 \%$ reduction, $n=7$, and $35 \pm 17 \%, n=7$, respectively) and re- 

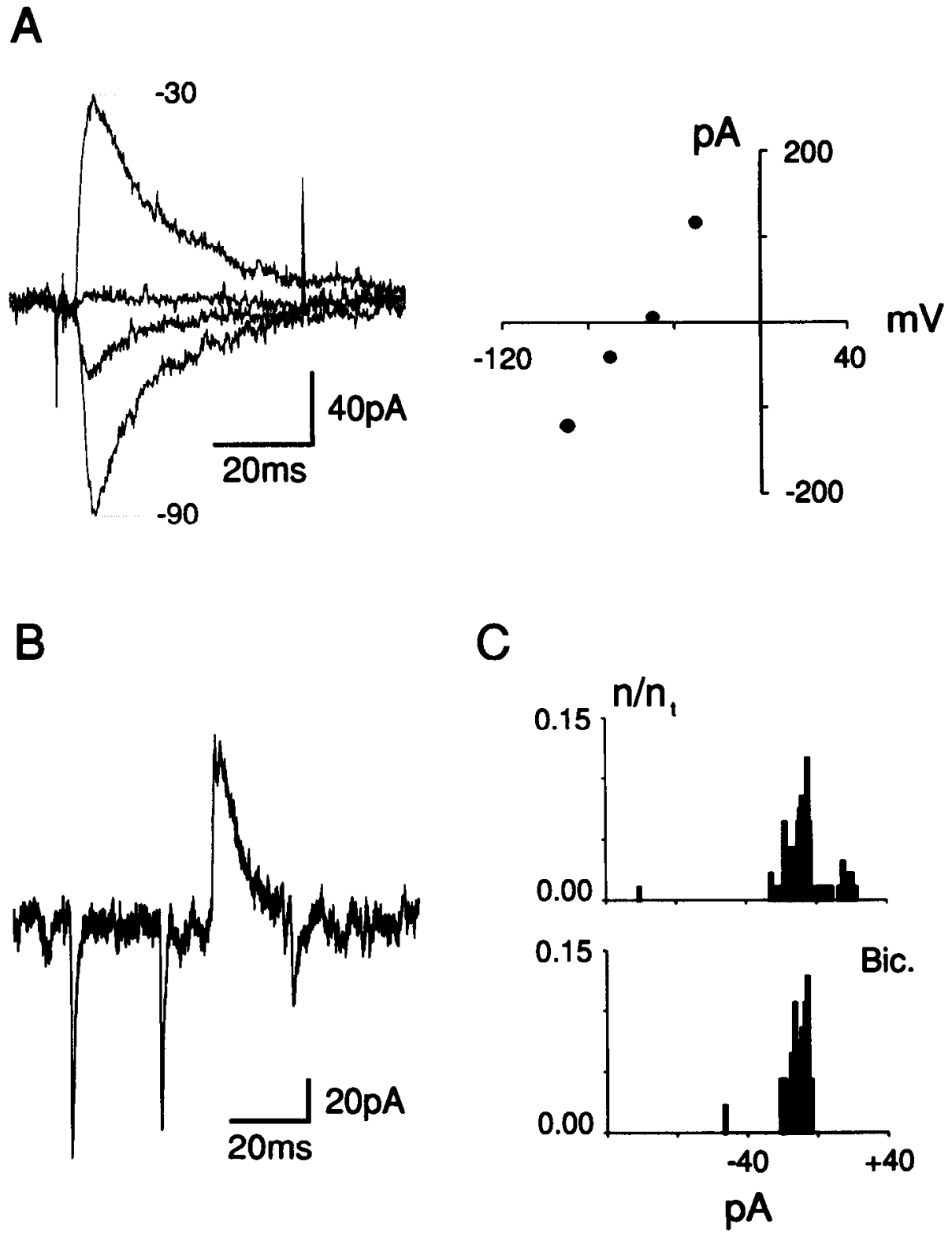

Figure 3. Characterization of evoked
inhibitory postsynaptic currents in tha-
lamic neurons in vitro. $A$, Reversal po-
tential. Left panel. The postsynaptic cell
was held at different membrane poten-
tials (indicated in millivolts; $20 \mathrm{mV}$
steps). Right panel, I-V relationship of
an evoked inhibitory postsynaptic cur-
rent (peak amplitude plotted against
holding potential). B, Spontaneous
postsynaptic currents at - $30 \mathrm{mV}$ hold-
ing potential. Inhibitory postsynaptic
currents were outwardly directed. C,
Frequency distribution of postsynaptic
current amplitudes at - $30 \mathrm{mV}$ holding
potential. Bin width, -1 pA. Outward
postsynaptic currents (upper panel) were
completely blocked by $50 \mu \mathrm{M}$ (-)-bi-
cuculline methochloride (Bic., lower
panel), indicating the presence of GA-
BAergic synaptic input. Number of de-
tected postsynaptic currents, 162 (con-
trol) and 192 (drug); recording duration,
30 sec.

versibly reduced HVA calcium currents by $65 \pm 8 \%(n=9)$ and $82 \pm 7 \%(n=9)$. EPSCs were reversibly depressed by 62 $\pm 10 \%(10 \mu \mathrm{M} ; n=12)$ and $79 \pm 6 \%(20 \mu \mathrm{M} ; n=7)$.

In Figure 6, effects of $\mathrm{Cd}$ on whole-cell calcium currents and glutamatergic synaptic transmission are summarized. It becomes evident that the reduced LVA calcium currents did not trigger transmission, as after complete blockade of HVA calcium currents, no postsynaptic responses were evoked. Thus, glutamatergic transmission in thalamic neurons was mediated mainly by HVA calcium channels. LVA calcium currents, however, might contribute to presynaptic calcium influx. This can only be investigated with strictly selective blockers of LVA calcium currents, which should reduce LVA calcium current amplitude by at least $50 \%$ without affecting HVA currents. We tested nickel, ethosuximide, and octanol, which have been reported to reduce this current type selectively (Fox et al., 1987a; Coulter et al., 1989b; Steriade et al., 1990). Nickel $(50 \mu \mathrm{M})$ and octanol $(20 \mu \mathrm{M})$ also affected HVA currents $(n=5$ and $n=6$, respectively). In the five cells tested, ethosuximide $(500 \mu \mathrm{M}) \mathrm{did}$ not affect LVA currents elicited from $-70 \mathrm{mV}$ holding potential. We next investigated which subtypes of HVA calcium currents induce evoked transmitter release.

Nifedipine. DHPs are organic agents that affect a distinct class of HVA calcium currents, named L-type. The effect of nifedipine $(50 \mu \mathrm{M})$ on whole-cell calcium currents and evoked glutamatergic EPSCs was tested. LVA calcium currents were not affected ( $n=5$; not shown). At a holding potential of $-70 \mathrm{mV}$, HVA calcium currents were reduced by $16 \pm 10 \%(n=6)$. The block was more pronounced if cells were held at $-40 \mathrm{mV}(30 \pm 10 \%$ inhibition; $n=6$; Fig. 7 A). Our results show that the effect of nifedipine on calcium currents is voltage dependent, as described previously (Rane et al., 1987). Nifedipine (50 $\mu \mathrm{M}) \mathrm{did}$ not affect evoked glutamatergic EPSCs $(n=6)$. As the depolarization during a spike may be too short to allow nifedipine to be effective, we tested the DHP effect on transmitter release during prolonged, potassium-evoked depolarization of presynaptic terminals. mFPSCs were recorded, as described above. If presynaptic terminals (along with the patched postsynaptic neu- 
A
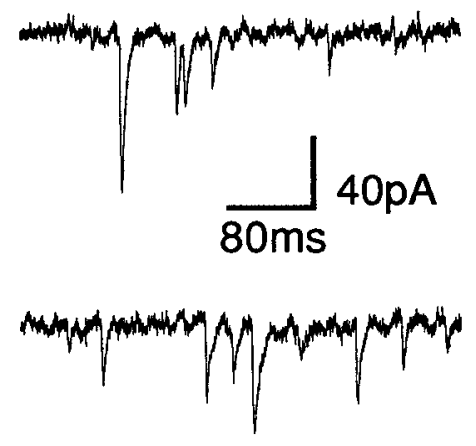

B

Figure 4. A, mEPSCs. Left panel, mEPSCs were recorded in $1 \mu \mathrm{M}$ TTX and $50 \mu \mathrm{M}(-)$-bicuculline methochloride at $-70 \mathrm{mV}$ holding potential. Right panel, Frequency distribution of mEPSC (solid bins) and noise (open bins) amplitudes. A total of 1453 mEPSCs were detected; recording duration, 150 sec. Bin width, 1 pA. $B$, Whole-cell calcium currents. Left panel, The cell was held at $-70 \mathrm{mV}$ and depolarized to different potentials (indicated in millivolts; 20 $\mathrm{mV}$ steps). The broken line indicates zero current. Right panel, $I-V$ relationship of whole-cell calcium currents. This cell lacked a prominent LVA current.

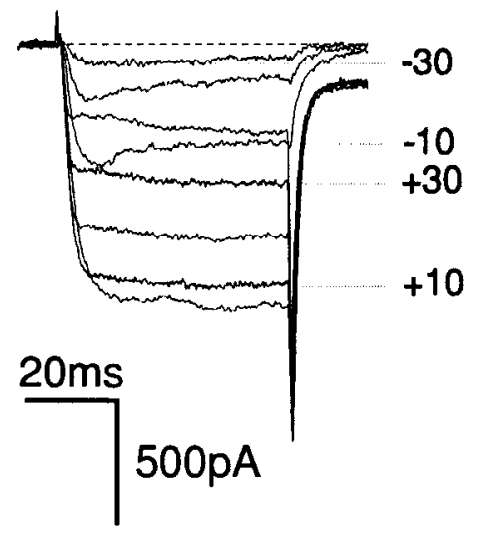

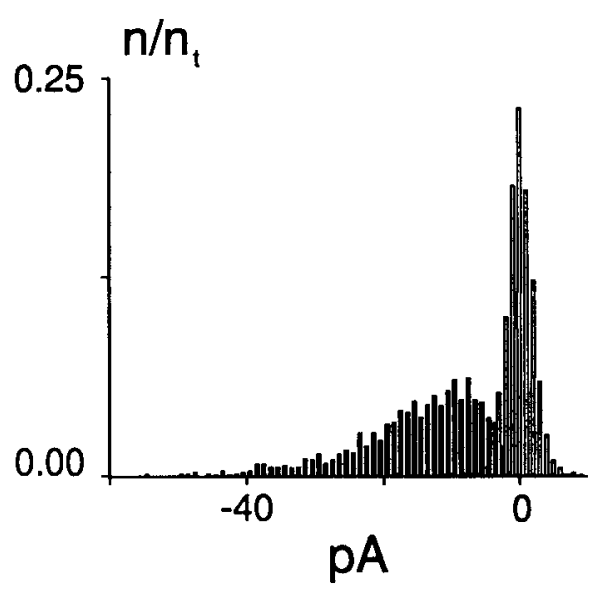

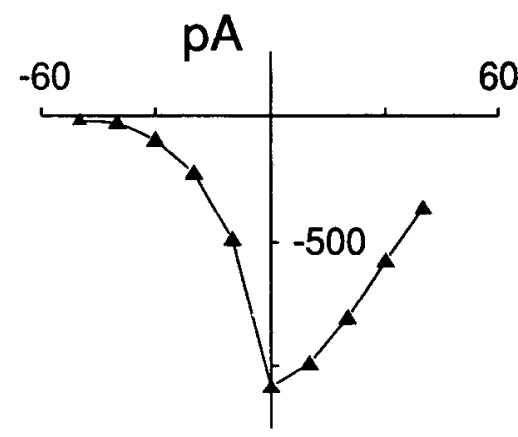

ron) were exposed to an elevated concentration of $\mathrm{KCl}(50 \mathrm{~mm})$ for $1 \mathrm{sec}$, the mEPSC frequency was increased by a factor of 16 $\pm 14(n=14)$. This potassium-evoked increase of transmitter release depended on presynaptic calcium influx, as it was reversibly reduced by $76 \pm 9 \%(n=6)$ with $\mathrm{Cd}(100 \mu \mathrm{M})$. Nifedipine $(50 \mu \mathrm{M})$ did not inhibit potassium-evoked increase in mEPSC frequency $(111 \pm 39 \%$ of control; $n=8)$. Using a similar approach, Brosius et al. (1990) also reported no DHP effect on transmitter release.

$\omega-C g T x$. The sea snail toxin $\omega-\mathrm{CgTx}$ is known to block a distinct component of neuronal HVA calcium currents irreversibly. We studied effects of $\omega$-CgTx on whole-cell calcium currents, evoked EPSCs, and mEPSCs. $\omega-\mathrm{CgTx}(2.5 \mu \mathrm{M})$ did not affect LVA calcium currents of thalamic neurons $(n=3$; not shown). HVA calcium currents, however, were irreversibly reduced by $32 \pm 11 \%(n=8$; Fig. $7 B)$. In four cells, HVA calcium currents were completely $\omega$-CgTx resistant. Glutamatergic EPSCs were inhibited by $32 \pm 19 \%(n=9$; Fig. $8 A, B)$. Synaptic transmission between four pairs (different cells as in HVA recordings) remained unaffected by $\omega-\mathrm{CgTx}$. In order to confirm that the applied concentration of $\omega$-CgTx was saturating, the concentration was raised to $5 \mu \mathrm{M}$ after calcium current or EPSC amplitudes had reached a stable level. No further reduction was observed (Figs. $7 B, 8 B$ ). In order to exclude interactions of $\omega$-CgTx with postsynaptic receptors, its effect on mEPSC amplitudes was test- ed. We found no change in frequency distributions of mEPSC amplitudes with $\omega$-CgTx $(n=4$; Fig. $8 C$ ), in agreement with previous reports (Kerr and Yoshikami, 1984; Sano et al., 1987). Thus, depression of EPSC amplitudes by $\omega-\mathrm{CgTx}$ was due to reduction of calcium influx into the presynaptic terminal. Our results indicate that the major component of presynaptic calcium influx triggering synaptic transmission was through nonL-/non-N-type HVA calcium channels. $\omega$-CgTx-sensitive calcium channels contributed a minor portion to presynaptic calcium current.

\section{Discussion}

We established a culture of thalamic neurons from embryonic rats with functional synaptic contacts. Two main types of thalamic neurons (relay neurons and interneurons) have been distinguished in vivo (Jones, 1985; Shepherd, 1990). Some thalamic neurons in vitro showed a neuritic arborization similar to that of relay neurons, but no attempt was made to identify neurons.

With simultaneous pair recordings, we studied evoked synaptic transmission by stimulating presynaptically and recording postsynaptic whole-cell currents. GABAergic and, more frequently, glutamatergic postsynaptic responses via NMD $\Lambda$ and non-NMDA postsynaptic receptors were evoked in cultured thalamic neurons. The transmitter phenotypes, found in vitro, agree with those previously described in slice and in in vivo prepa- 

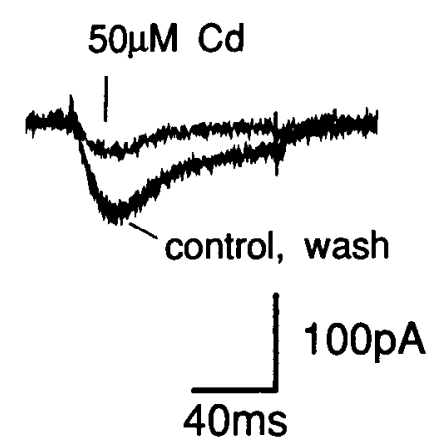

B

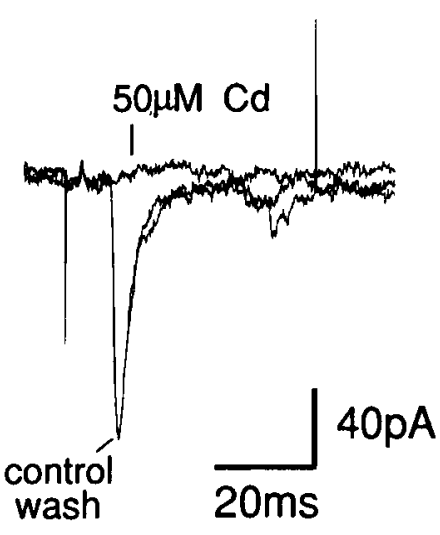

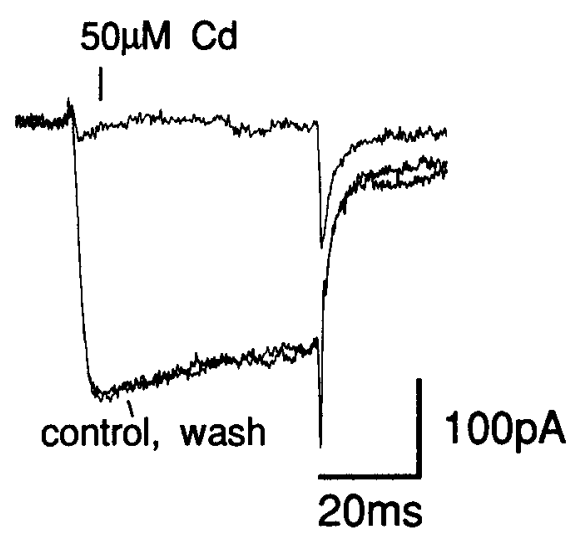

C

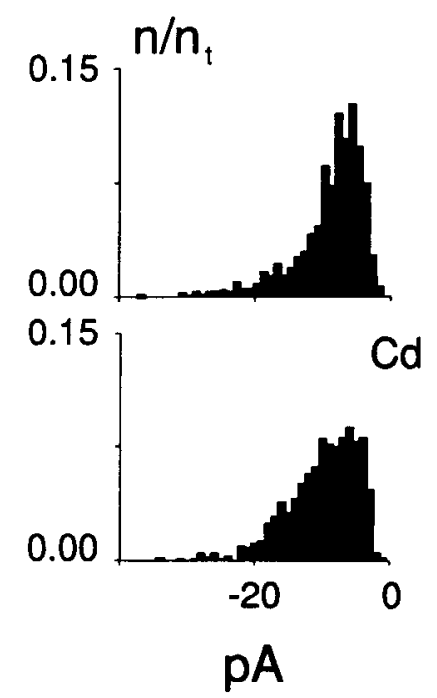

Figure 5. Effects of $50 \mu \mathrm{M} \mathrm{Cd}$ on wholecell calcium currents and excitatory synaptic transmission. $A$, Effects on whole-cell calcium currents. Left panel, LVA calcium current is reversibly reduced; depolarizing step from -70 to $-30 \mathrm{mV}$. Right panel, Complete and reversible block of HVA calcium current; depolarizing step from -70 to +10 $\mathrm{mV} . B$, EPSCs were completely and reversibly abolished; holding potential, $-70 \mathrm{mV}$. C, Cd had no effect on mEPSC amplitudes: frequency distribution of mEPSC amplitudes before (upper pan$e l$ ) and during (lower panel) superfusion with $C d$. Bin width, $1 \mathrm{pA}$. Number of mEPSCs was 1154 before and 1131 during $\mathrm{Cd}$ application; recording $\mathrm{du}$ ration, $100 \mathrm{sec}$; holding potential, -70 $\mathrm{mV}$. rations. Both subtypes of ionotropic excitatory amino acid receptors (NMDA and non-NMDA) mediate synaptic transmission in thalamic neurons (Salt, 1987; de Curtis et al., 1989; Scharfman et al., 1990). Inhibitory synaptic input has been shown to be GABAergic (Salt, 1989; Paré, 1991). EPSCs due to spontaneous, quantal transmitter release have not been described in thalamic neurons so far. Like in hippocampal neurons (Brown et al., 1979; Bekkers et al., 1990; Finch et al., 1990), amplitude distributions of mEPSCs were skewed presumably due to either variable quantal size or release at synaptic terminals differing in electrotonic distance (Bekkers et al., 1990).

Whole-cell LVA and HVA calcium currents were present in thalamic neurons in vitro as suggested by the previous work of Jahnsen and Llinás (1984) and confirmed by Coulter et al. (1989a). These authors report that relay neurons from the ventrobasal complex expressed LVA calcium currents with amplitudes, which were large relative to those of IIVA currents. We found that $10 \%$ of thalamic neurons in vitro had prominent LVA calcium current components, indicating the presence of different neuronal cell types.

Different types of HVA calcium channels have been distinguished due to their sensitivity to DHPs and $\omega-\mathrm{CgTx}$ (see re-

\section{$\%$ Inhibition}

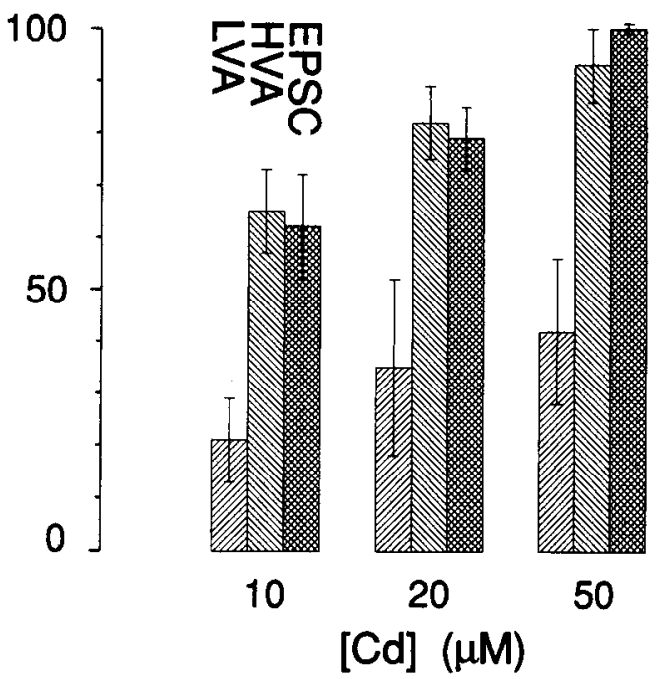

Figure 6. Effects of micromolar concentrations of $\mathrm{Cd}$ on whole-cell calcium currents and EPSCs. Vertical axis, percentage inhibition; error bars indicate SD. 
A

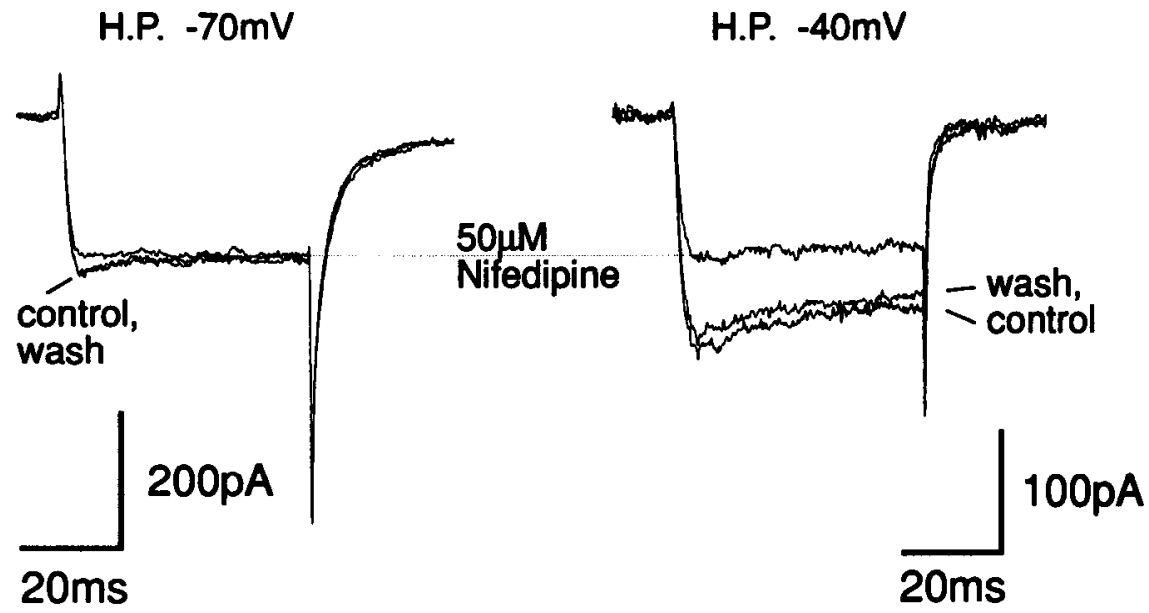

Figure 7. Pharmacological character-

8 ization of whole-cell HVA calcium currents. $A$, Voltage dependence of the DHP effect. Left panel, At $-70 \mathrm{mV}$ holding potential, nifedipine reversibly blocked a small component of HVA calcium current. Right panel, At -40 $\mathrm{mV}$ holding potential, the amount of inhibition was increased. $B$, Effect of $\omega$ CgTx on whole-cell calcium currents. Left panel, HVA calcium current (depolarizing step from -70 to $+10 \mathrm{mV}$ ) was irreversibly reduced by $\omega$-CgTx (2.5 $\mu \mathrm{M})$. Right panel, Relative amplitude of HVA calcium current plotted against time. The reduction of HVA calcium current by $\omega-\mathrm{CgTx}(2.5 \mu \mathrm{M})$ was distinct from rundown. It did not increase by subsequent elevation of the concentration to $5 \mu \mathrm{M}$.

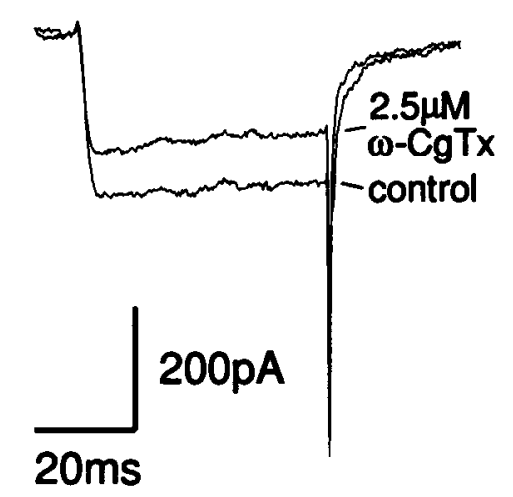

Rel. Ampl. (\%)

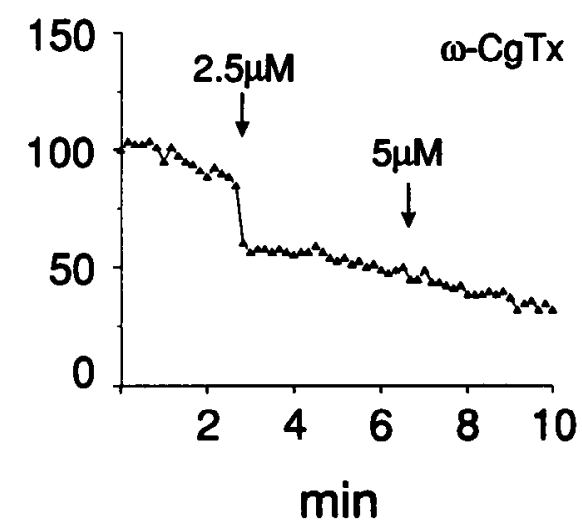

views cited above). Whole-cell calcium currents of thalamic neurons were blocked by one-third by $\omega-\mathrm{CgTx}$; in some cells, however, calcium currents remained unaffected. A high concentration of the DHP nifedipine blocked a small component of HVA calcium current. The block was increased at a more depolarized holding potential and was thus voltage dependent (Rane et al., 1987). Our pharmacological characterization of HVA calcium currents in thalamic neurons in vitro showed the presence of DHP- and $\omega$-CgTx-sensitive current components, as has been shown for other central neurons (Mogul and Fox, 1991; Regan et al., 1991). The major portion of calcium influx, however, was through non-L-/non-N-type calcium channels, which have been found in other regions of the rat brain (Mogul and Fox, 1991; Regan et al., 1991). The analysis of the calcium channel types should be facilitated with pharmacological tools such as recently isolated fractions from spider venom (Llinás et al., 1989; Mintz et al., 1991) and more structural information on calcium channel proteins (Catterall, 1991; Tsien et al., 1991) become available.

The aim of this study was to characterize presynaptic calcium currents triggering synaptic transmission. Since the biophysical properties of presynaptic calcium currents could not be measured directly, we used a pharmacological approach comparing the sensitivities of whole-cell calcium currents and evoked EPSCs to different blockers.

It has been suggested that during an action potential a significant amount of calcium ions flows through LVA channels (McCobb and Beam, 1991). Thus, LVA calcium channels might mediate a portion of presynaptic calcium influx, which is comparable in size to that through HVA channels. We investigated whether presynaptic LVA calcium current induces evoked transmitter release. As previously described for other cell types (Carbone and Swandulla, 1989), micromolar concentrations of Cd selectively blocked HVA calcium currents of thalamic neurons. With HVA calcium currents completely abolished and LVA currents partially reduced by $50 \mu \mathrm{M} \mathrm{Cd}$, no synaptic responses could be evoked. Thus, reduced LVA calcium currents could not trigger synaptic transmission, confirming previous suppositions (Holz et al., 1988; Kamiya et al., 1988). These experiments do not exclude, however, that LVA currents contribute to the calcium influx into presynaptic terminals. This can only be tested if strictly selective LVA channel blockers become 
A

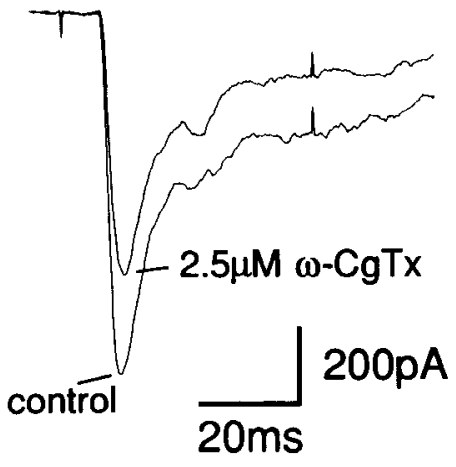

B

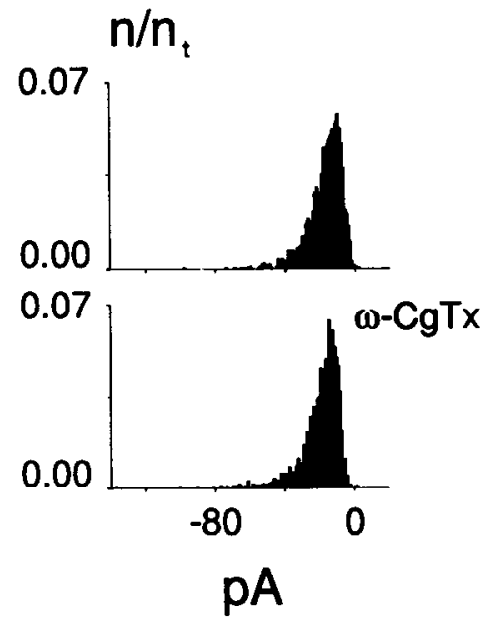

Rel. Ampl. (\%)

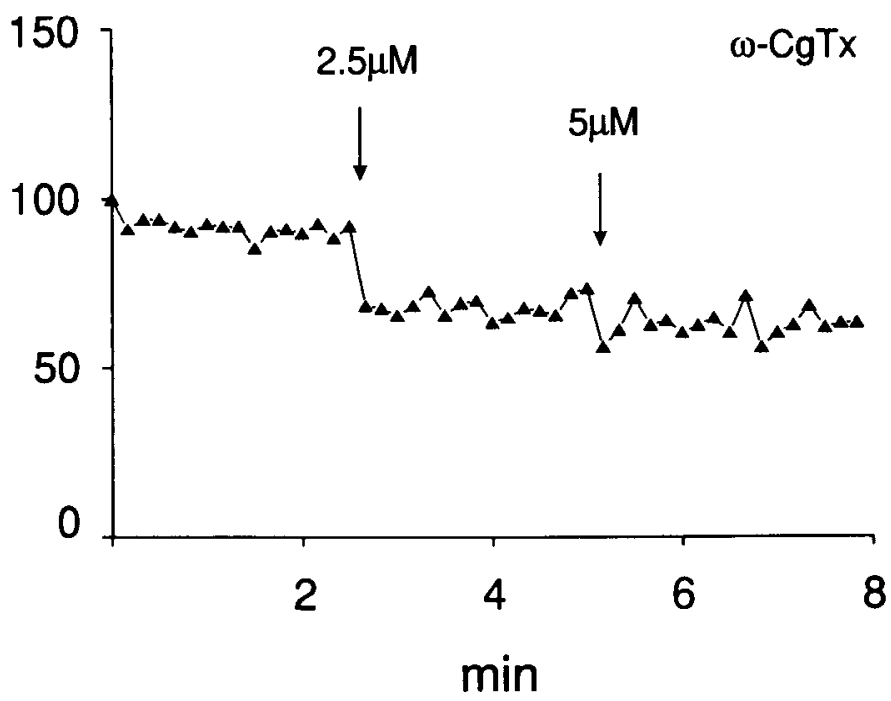

Figure 8. Effects of $\omega$-CgTx on EPSCs and mEPSCs. $A$, Reduction of EPSC amplitude by $\omega-\operatorname{CgTx}(2.5 \mu \mathrm{M})$ at -70 $\mathrm{mV}$ holding potential. $B$, The reduction was not due to rundown and was not incrcased by an clevated concentration. $C$, The effect on evoked EPSCs is due to a reduction of presynaptic calcium current. Frequency distributions of mEPSC amplitudes were similar before (upper panel) and in the presence of $\omega$ $\mathrm{CgTx}(2.5 \mu \mathrm{M}$; lower panel). The number of detected mEPSCs was 2243 under control conditions and 2081 with $\omega$-CgTx; recording duration, $1 \mathrm{~min}$; bin width, 1 pA; holding potential, $-70 \mathrm{mV}$.

available. Interestingly, Lemos and Nowycky (1989) and Yawo (1990) did not detect LVA calcium channels in vertebrate presynaptic terminals.

We further analyzed the types of presynaptic HVA calcium current that mediate evoked transmitter release. Previous investigations have led to the conclusion that DHP-insensitive but $\omega$-CgTx-sensitive calcium channels play a major role in synaptic transmission, with some evidence obtained by electrophysiological studies (Kamiya et al., 1988; Dutar et al., 1989; Krishtal et al., 1989). A major or exclusive role of HVA calcium channels, which cannot be classified as L-, or N-type, in synaptic transmission has been proposed previously (Seabrook and Adams, 1989; Suszkiw et al., 1989; Charlton and Augustine, 1990). In thalamic neurons in vitro, glutamatergic synaptic transmission was insensitive to nifedipine and was only blocked by onethird by a saturating concentration of $\omega-\mathrm{CgTx}$. The predominant part of the presynaptic calcium influx was thus through non-L/non-N-type HVA calcium channels. We suppose that synaptic transmission between central neurons might be mediated by different types of calcium channels, and that the relative contribution of a specific type may vary in different brain regions.

\section{References}

Aosaki T, Kasai H (1989) Characterization of two kinds of highvoltage-activated $\mathrm{Ca}$-channel currents in chick sensory neurons. Differential sensitivity to dihydropyridines and $\omega$-conotoxin GVIA. Pfluegers Arch 414:150-156.

Augustine GJ, Charlton MP, Smith SJ (1987) Calcium action in synaptic transmitter release. Annu Rev Neurosci 10:633-693.

Bean BP (1989) Classes of calcium channels in vertebrate cells. Annu Rev Physiol 51:367-384.

Bekkers JM, Richerson GB, Stevens CF (1990) Origin of variability in quantal size in cultured hippocampal neurons and hippocampal slices. Proc Natl Acad Sci USA 87:5359-5362.

Brosius DC, Hackett JT, Tuttle JB (1990) Presynaptic calcium currents evoking quantal transmission from avian ciliary ganglion neurons. Synapse 5:313-323.

Brown TH, Wong RKS, Prince DA (1979) Spontaneous miniature synaptic potentials in hippocampal neurons. Brain Res 177:194-199. 
Carbone E, Lux HD (1984) A low-voltage-activated, fully inactivating Ca channel in vertebrate neurones. Nature 310:501-502.

Carbone E, Swandulla D (1989) Neuronal calcium channels: kinetics, blockade and modulation. Prog Biophys Mol Biol 54:31-58.

Catterall WA (1991) Functional subunit structure of voltage-gated calcium channels. Science 253:1499-1500.

Charlton MP, Augustine GJ (1990) Classification of presynaptic calcium channels at the squid giant synapse: neither $\mathrm{T}-, \mathrm{L}-$, nor $\mathrm{N}$-type. Brain Res 525:133-139.

Coulter DA, Huguenard JR, Prince DA (1989a) Calcium currents in rat thalamocortical relay neurones: kinetic properties of the transient, low-threshold current. J Physiol (Lond) 414:587-604.

Coulter DA, Huguenard JR, Prince DA (1989b) Specific petit mal anticonvulsants reduce calcium currents in thalamic neurons. Neurosci Lett 98:74-78.

De Camilli P, Jahn R (1990) Pathways to regulated exocytosis in neurons. Annu Rev Physiol 52:625-645.

de Curtis M, Spreafico R, Avanzini G (1989) Excitatory amino acids mediate responses elicited in vitro by stimulation of cortical afferents to reticularis thalami neurons of the rat. Neuroscience $33: 275-283$.

Dutar P, Rascol O, Lamour Y (1989) $\omega$-Conotoxin GVIA blocks synaptic transmission in the CAl field of the hippocampus. Eur J Pharmacol 174:261-266.

Edmonds B, Klein M, Dale N, Kandel ER (1990) Contributions of two types of calcium channels to synaptic transmission and plasticity. Science 250:1142-1147.

Fedulova SA, Kostyuk PG, Veselovsky NS (1985) Two types of calcium channels in the somatic membrane of new-born rat dorsal root ganglion neurones. J Physiol (Lond) 359:431-446.

Finch DM, Fisher RS, Jackson MB (1990) Miniature excitatory synaptic currents in cultured hippocampal neurons. Brain Res 518:257268.

Fox AP, Nowycky MC, Tsien RW (1987a) Kinetic and pharmacological properties distinguishing three types of calcium currents in chick sensory neurones. J Physiol (Lond) 394:149-172.

Fox AP, Nowycky MC, Tsien RW (1987b) Single-channel recordings of three types of calcium channels in chick sensory neurones. J Physiol (Lond) 394:173-200.

Gottmann K, Rohrer H, Lux HD (1991) Distribution of $\mathrm{Ca}^{2+}$ and $\mathrm{Na}^{+}$conductances during neuronal differentiation of chick DRG precursor cells. J Neurosci 1 1:3371-3378.

Gray WR, Olivera BM, Cruz LJ (1988) Peptide toxins from venomous Conus snails. Annu Rev Biochem 57:665-700.

Hamill OP, Marty A, Neher E, Sakmann B, Sigworth FJ (1981) Improved patch-clamp techniques for high-resolution current recording from cells and cell-free membrane patches. Pfluegers Arch 391:85100 .

Hess P (1990) Calcium channels in vertebrate cells. Annu Rev Neurosci $13: 337-356$

Hirning LD, Fox AP, McCleskey EW, Olivera BM, Thayer SA, Miller $\mathrm{RJ}$, Tsien RW (1988) Dominant role of $\mathrm{N}$-type $\mathrm{Ca}^{2+}$ channels in evoked release of norepinephrine from sympathetic neurons. Science 239:57-61.

Holz GG IV, Dunlap K, Kream RM (1988) Characterization of the electrically evoked release of substance $P$ from dorsal root ganglion neurons: methods and dihydropyridine sensitivity. J Neurosci 8:463_ 471 .

Horne AL, Kemp JA (1991) The effect of $\omega$-conotoxin GVIA on synaptic transmission within the nucleus accumbens and hippocampus of the rat in vitro. Br J Pharmacol 103:1733-1739.

Jahnsen H, Llinás R (1984) Ionic basis for the electroresponsiveness and oscillatory properties of guinea-pig thalamic neurones in vitro. $\mathrm{J}$ Physiol (Lond) 349:227-247.

Jones EG (1985) The thalamus. London: Plenum.

Kamiya H, Sawada S, Yamamoto C (1988) Synthetic $\omega$-conotoxin blocks synaptic transmission in the hippocampus in vitro. Neurosci Lett 91:84-88

Katz B (1969) The release of neural transmitter substances. Liverpool: Liverpool University Press.

Kerr LM, Yoshikami D (1984) A venom peptide with a novel presynaptic blocking action. Nature 308:282-284.

Krishtal OA, Petrov AV, Smirnov SV, Nowycky MC (1989) Hippocampal synaptic plasticity induced by excitatory amino acids includes changes in sensitivity to the calcium channel blocker, $\omega$-conotoxin. Neurosci Lett 102:197-204.
Lemos JR, Nowycky MC (1989) Two types of calcium channels coexist in peptide-releasing vertebrate nerve terminals. Neuron $2: 1419-1426$.

Llinás R, Sugimori M, Lin JW, Cherksey B (1989) Blocking and isolation of a calcium channel from neurons in mammals and cephalopods utilizing a toxin fraction (FTX) from funnel-web spider poison. Proc Natl Acad Sci USA 86:1689-1693.

McCobb DP, Beam KG (1991) Action potential waveform voltageclamp commands reveal striking differences in calcium entry via low and high voltage-activated calcium channels. Neuron 7:119-127.

Miller RJ (1987) Multiple calcium channels and neuronal function. Science 235:46-52.

Miller RJ (1990) Receptor-mediated regulation of calcium channels and neurotransmitter release. FASEB J 4:3291-3299.

Mintz IM, Venema VJ, Adams ME, Bean BP (1991) Inhibition of Nand L-type $\mathrm{Ca}^{2+}$ channels by the spider venom toxin $\omega$-Aga-IIIA. Proc Natl Acad Sci USA 88:6628-6631.

Mogul DJ, Fox AP (1991) Evidence for multiple types of $\mathrm{Ca}^{2+}$ channels in acutely isolated hippocampal CA3 neurones of the guinea-pig. I Physiol (Lond) 433:259-281.

Obaid AL, Flores R, Salzberg BM (1989) Calcium channels that are required for secretion from intact nerve terminals of vertebrates are sensitive to $\omega$-conotoxin and relatively insensitive to dihydropyridines. J Gen Physiol 93:715-729.

Paré D, Dussi RC, Steriade M (1991) Three types of inhibitory postsynaptic potentials generated by interneurons in the anterior thalamic complex of cat. J Neurophysiol 66:1190-1204.

Perney TM, Hirning LD, Leeman SE, Miller RJ (1986) Multiple calcium channels mediate neurotransmitter release from peripheral neurons. Proc Natl Acad Sci USA 83:6656-6659.

Plummer MR, Hess P (1991) Reversible uncoupling of inactivation in N-type calcium channels. Nature 351:657-659.

Plummer MR, I ogothetis DE, Hess P (1989) Elementary properties and pharmacological sensitivities of calcium channels in mammalian peripheral neurons. Neuron 2:1453-1463.

Rane SG, Holz GG IV, Dunlap K (1987) Dihydropyridine inhibition of neuronal calcium current and substance $P$ release. Pfluegers Arch 409:361-366.

Regan LJ, Sah DWY, Bean BP (1991) Ca Ca $^{21}$ channels in ral central and peripheral neurons: high-threshold current resistant to dihydropyridine blockers and $\omega$-conotoxin. Neuron 6:269-280.

Reynolds 1J, Wagner JA, Snyder SH, I hayer SA, Olivera BM, Miller RJ (1986) Brain voltage-sensitive calcium channel subtypes differentiated by $\omega$-conotoxin fraction GVIA. Proc Natl Acad Sci USA 83: 8804-8807.

Salt TE (1987) Excitatory amino acid receptors and synaptic transmission in the rat ventrobasal thalamus. J Physiol (I ond) 391:499510.

Salt TE (1989) Gamma-aminobutyric acid and afferent inhibition in the cat and rat ventrobasal thalamus. Neuroscience 28:17-26.

Sano K, Enomoto K, Maeno T (1987) Effects of synthetic $\omega$-conotoxin, a new type $\mathrm{Ca}^{2+}$ antagonist, on frog and mouse neuromuscular transmission. Eur J Pharmacol 141:235-241.

Sayer RJ, Redman SJ, Andersen P (1989) Amplitude fluctuations in small EPSPs recorded from CAl pyramidal cells in the guinea pig hippocampal slice. J Neurosci 9:840-850.

Scharfman HE, Lu SM, Guido W, Adams PR, Sherman SM (1990) $N$-methyl-D-aspartate receptors contribute to excitatory postsynaptic potentials of cat lateral geniculate neurons recorded in thalamic slices. Proc Natl Acad Sci USA 87:4548-4552.

Scholz KP, Miller RJ (1991) Analysis of adenosine actions on $\mathrm{Ca}^{2+}$ currents and synaptic transmission in cultured rat hippocampal pyramidal neurons. J Physiol (Lond) 435:373-393.

Schroeder JE, Fischbach PS, Mamo M, McCleskey EW (1990) Two components of high-threshold $\mathrm{Ca}^{2+}$ current inactivate by different mechanisms. Neuron 5:445-452.

Seabrook GR, Adams DJ (1989) Inhibition of neurally-evoked iransmitter release by calcium channel antagonists in rat parasympathetic ganglia. Br J Pharmacol 97:1125-1136.

Shepherd GM (1990) The synaptic organization of the brain, 3rd ed. Oxford: Oxford University Press

Sher E, Clementi F (1991) $\omega$-Conotoxin-sensitive voltage-operated calcium channels in vertebrate cells. Neuroscience 42:301-307.

Smith SJ, Augustine GJ (1988) Calcium ions, active zones and synaptic transmitter release. Trends Neurosci 1 1:458-464.

Stanley EF, Atrakchi AH (1990) Calcium currents recorded from a 
vertebrate presynaptic nerve terminal are resistant to the dihydropyridine nifedipine. Proc Natl Acad Sci USA 87:9683-9687.

Stanley EF, Goping G (1991) Characterization of a calcium current in a vertebrate cholinergic presynaptic nerve terminal. J Neurosci 11: 985-993.

Stanley EF, Nowycky MC, Triggle DJ, eds (1991) Annals of the New York Academy of Sciences, Vol 635, Calcium entry and action at the presynaptic nerve terminal. New York: New York Academy of Sciences.

Steriade M, Jones EG, Llinás RR (1990) Thalamic oscillations and signaling. New York: Wiley.

Streit J, Lux HD (1989) Distribution of calcium currents in sprouting PC12 cells. J Neurosci 9:4190-4199.

Suszkiw JB, Murawsky MM, Shi M (1989) Further characterization of phasic calcium influx in rat cerebrocortical synaptosomes: inferences regarding calcium channel type(s) in nerve endings. J Neurochem 52:1260-1269.
Swandulla D, Armstrong CM (1989) Calcium channel block by cadmium in chicken sensory neurons. Proc Natl Acad Sci USA 86:17361740.

Swandulla D, Carbone E, Lux HD (1991) Do calcium channel classifications account for neuronal calcium channel diversity? Trends Neurosci 14:46-51.

Tsien RW, Lipscombe D, Madison DV, Bley KR, Fox AP (1988) Multiple types of neuronal calcium channels and their selective modulation. Trends Neurosci 11:431-438.

Tsien RW, Ellinor PT, Horne WA (1991) Molecular diversity of voltage-dependent $\mathrm{Ca}^{2+}$ channels. Trends Pharmacol Sci 12:349-354.

Wray DW, Norman RI, Hess P, eds (1989) Annals of the New York Academy of Sciences, Vol 560, Calcium channels: structure and function. New York: New York Academy of Sciences.

Yawo H (1990) Voltage-activated calcium currents in presynaptic nerve terminals of the chicken ciliary ganglion. J Physiol (Lond) 428:199213. 